\section{Artigo Livre}

* Recebido em: 09.09.2018. Aprovado em: 17.11.2018.

** 1 Mestrando do Programa de PósGraduação da Universidade Estadual de Campinas (Unicamp). Email: aalins@hotmail.com

\section{Origem, forma e conteúdo da expressão artística: Aby Warburg com Franz Boas?}

Origin, formation and content of his artistic composition: Aby Warburg with Franz Boas?

Artur André Lins*
Resumo: Na fronteira da história da arte com a antropologia cultural, o proposta desse ensaio almeja promover o encontro das ideias de Aby Warburg com as de Franz Boas. O mote para a costura teórica desse autores é exatamente o problema da origem da expressão artística, ressaltando, para tanto, questões relativas à forma e conteúdo. Observamos que, por um lado, a origem da expressão artística encontra explicação pela ancestralidade dos hábitos motrizes, na fabricação técnica dos objetos da vida cotidiana, cuja necessidade psicológica se acha no prazer do virtuose em dominar formas compelxas. Por outro lado, a origem da expressão artística funda-se na ordenação cosmológica do mundo, no efeito de vinculação simbólica, cuja necessidade psicológica se exerce pela empatia mimética que visa apreender o imponderável da existência.

Palavras-chave: Expressão artística; forma e conteúdo; Aby

Warburg; Franz Boas
Abstract: On the frontier of art history and cultural anthropology, the purpose of this essay aims to promote the meeting of Aby Warburg's ideas with those of Franz Boas. The motto for the theoretical sewing of these authors is exactly the problem of the origin of artistic expression, highlighting, therefore, issues related to form and content. We observe that, on the one hand, the origin of artistic expression is explained by the ancestry of the driving habits, in the technical fabrication of the objects of everyday life, whose psychological need lies in the pleasure of virtuosity in mastering compelx forms. On the other hand, the origin of artistic expression is based on the cosmological ordering of the world, on the effect of symbolic attachment, whose psychological need is exerted by the mimetic empathy that seeks to grasp the imponderable existence. Keywords: Artistic expression; form and content; Aby Warburg; Franz Boas 
"Queremos escalar o teto da morada do mundo, voltar a cabeça para cima e pensar no que Goethe chegou a dizer: não fosse o olho algo solar, como poderia contemplar o Sol? Toda a humanidade se encontra na veneração do Sol. E tomá-lo como símbolo que nos alça das profundezas da noite é direito tanto do selvagem como do erudito."

- Aby Warburg

"Nós vimos que o desejo da expressão artística é universal. (...) É a qualidade de sua experiência, $e$ não uma diferença de composição mental que determina a diferença entre a produção e apreciação da arte moderna e primitiva."

Franz Boas

Pretendemos lidar com o problema da origem. O que é a origem? Um antecedente para o qual se reporta um sucedente? Um marco temporal cronológico? Um marco espacial topográfico? Sorte de acontecimento deflagrado por um ponto crítico na consequência dos eventos? Algo como o elemento demiúrgico da narrativa mítica? Símbolo da tradição e encenação performática do "desde sempre"? Prova da autenticidade do estilo? Afirmação histórica do contexto particular? Condição humana primordial da expressão? Afinal, o que o problema da origem diz sobre os caminhos da expressão artística humana?

No interstício disciplinar da antropologia cultural com a história da arte, o problema da origem será tratado a partir do reencontro das ideias de Aby Warburg e Franz Boas. Para levar a termo tamanho encontro, nos concentramos em um tópico de análise: a relação entre forma e conteúdo da expressão artística. Dessa forma, faremos recurso aos textos de Franz Boas na medida em que este autor esboça uma crítica ao difusionismo e ao evolucionismo ancorando-se em uma perspectiva dada ao particularismo do contexto histórico-etnológico. Ainda, em Franz Boas, encontramos uma proposição segundo a qual a distinção entre forma e conteúdo é mantida para a melhor compreensão do crescimento dos estilos. Por outro lado, queremos observar o modo como Aby Wargburg entende a gênese dos símbolos a partir de uma perspectiva que coloca no centro do argumento o conceito de "sobrevivência" (Nachleben). Seguindo, podemos novamente perceber, em Aby Warburg, o modo como forma e conteúdo se interpenetram no processo da empatia, tornando-se termos indissociáveis para uma história cultural da arte.

O texto que então começa a se erguer opta por uma estrutura ensaística, cuja proposta é uma narrativa corrida e sinuosa. Um texto em forma de ensaio confere maior liberdade para o tratamento das ideias e, adiante, nos empenhamos criativamente ao diálogo entre dois autores que se aproximam e se distanciam em vários aspectos. Ambos judeus, indignados com o momento político que a Europa vivia na primeira metade do século XX, se destacam, entre outros, por uma defesa enfática da igualdade moral entre os povos, resguardadas as suas diferenças humanas. A crítica ao conceito de raça, que visava um princípio biológico para nivelar os diversos

Dossiê Consumo e Subjetividade 
gêneros humanos, bem como um anti-sionismo galopante, sobretudo na Alemanha, certamente marcaram o projeto intelectual de toda uma geração. Este, assim pensamos, buscou de maneira intransigente afirmar a irredutibilidade das culturas humanas, uma diferença radical da experiência possível descreditava as tentativas de nivelar evolutivamente. Aquele, por sua vez, buscou olhar uma história um tanto misturada, escrita por linhas embaralhadas que se convergem para a composição de uma pintura heteróclita em que a origem - o primitivo - não se tratava de uma primeira etapa no longo processo de evolução civilizatória, mas uma condição primordial que permanece em latência, viva, tanto no selvagem quanto no erudito.

A inspiração para elaborar a proposta desse ensaio deveu-se principalmente a partir da troca de cartas entre Aby Warburg e Franz Boas (GUIDI, 2007). Reproduzo, em seguida, dois trechos desse encontro:

Aby Warburg para Franz Boas, 13 de dezembro de 1924:

Em substância, o problema da influência da antiguidade é meramente o resíduo fenomenológico de um problema psicológico completamente interno; a memória individual de uma imagem - uma imagem no sentido mais geral deve ser considerada dentro de um contexto histórico como uma função social causada pela condição dinâmica da mesma individualidade colocada na eterna alternância entre descarga dinâmica e supressão intencional.

Franz Boas para Aby Warburg, 14 de janeiro de 1925:
E verdade que a ideia da serpente com chifres ou emplumada é muito geral na América. Não está de forma alguma confinado à América Central e ao Sudoeste, mas ocorre também no Nordeste e na Costa Noroeste, e estou inclinado a pensar que uma difusão geral dessa ideia ocorreu em qualquer época anterior. Isso, no entanto, não nos justificaria em identificar as formas específicas com a ideia que cada uma tomou em diferentes províncias culturais. Por exemplo, certamente não há nada que indique que a serpente emplumada de duas cabeças da Costa Noroeste tenha qualquer conexão psicológica ou cultural com a serpente emplumada do México.

No primeiro trecho, Warburg demonstra haver lido com atenção as ideias de Franz Boas. Primeiro, como se vê, o problema da influência da antiguidade e, por consequência, o problema da memória individual de uma imagem - ambas as preocupações tipicamente warburguianas - se cruzam com termos boasianos, entre contexto histórico e função social, importa a compreensão das condições dinâmicas decorrentes da alternância entre "descarga dinâmica" e "supressão intencional", ou seja, entre estilo convencional e criatividade individual. Por outro lado, Franz Boas já assinala uma diferença fundamental com o pensamento de Aby Warburg, quer dizer, as ideias representadas pelos símbolos dependem mais das reações coletivas às convenções simbólicas, não havendo conexão psicológica entre imagens que se repetem ao longo do tempo e ao longo do espaço.

Em um primeiro movimento de aproximação das ideias dos autores estudados, lidaremos com a questão principal: existe algo como uma "origem" para a expressão artística humana? Assim, pensamos ser interessante começar pelo modo como cada um, à sua

Dossiê Consumo e Subjetividade 
maneira, apresenta a relação entre forma e conteúdo na expressão artística. Como adiante pretendemos demonstrar, a origem da expressão artística encontra fontes distintas, não necessariamente contraditórias entre si, mas, por serem alternativas, são compatíveis. Por um lado, a origem reflete o virtuosismo da técnica, o processo instrumental da fabricação de objetos de apreciação estética. Por outro lado, a origem espelha o processo religioso de apreensão do imponderável, o enigma da vinculação simbólica e da ordenação cosmológica do mundo.

Quando pensamos na relação entre forma e conteúdo, especialmente para o campo de estudos da arte e da cultura, nos dirigimos a um longo debate filosófico. Forma e conteúdo são palavras que designam momentos distintos de algo aparentemente comum: a experiência. No entanto, é justamente a noção de experiência alvo de uma controvérsia conceitual profunda. Por exemplo, assumir uma posição diante do estatuto da experiência implica no modo como a verdade, a moral e o belo são ajuizados. A pergunta consequente seria: de qual experiência pretendemos falar? Da experiência estética, por um lado, e da experiência extática, por outro, e como são desencadeadas por efeito das obras do trabalho humano. Afinal, o que é a experiência? Como se dá a experiência? O debate filosófico possui rótulos para classificar o modo como os filósofos se colocam diante dessa palavra. Entre o objetivismo e o subjetivismo, uns são idealistas transcendentais, outros são realistas empíricos, ou até materialistas transcendentais, enfim. Há uma diversidade razoável que extrapola os limites dessa reflexão.
Entretanto, uma definição mínima nos parece um bom ponto de partida. A experiência se coloca como um intermediário entre sujeito e objeto, interioridade e exterioridade. Como a experiência é compreendida depende fundamentalmente da ênfase dada a cada um desses polos e as suas interações. Forma e conteúdo, assim, são momentos de uma relação entre sujeito e objeto que revela a condição de possibilidade da experiência. O sujeito, invariavelmente, se depara com a experiência de uma afecção sensível que lhe causa algum tipo de impressão sensorial. Essa impressão gerada pela afecção sensível, para tornar-se inteligível, é organizada - trabalhada - pelo intelecto, que traduz os dados brutos da recepção e, ativamente, transforma-os em percepção. A forma é esse elemento racional da intuição empírica, o próprio modal da matéria que corresponde a um instinto ordenador, sendo a percepção do padrão (unidade) no diverso da sensibilidade. O conteúdo, por sua vez, sendo o substrato da forma, como aquilo que a preenche, oferece o material empírico onde são alojados os sentidos, a significância e o conceito. Forma e conteúdo, como se diz, são momentos de um mesmo instante, mas variam conforme o tipo de fruição da experiência possível segundo as determinações históricoculturais. A forma estaria para a linguagem assim como o conteúdo estaria para o mito? Vejamos.

Começamos com o texto de Franz Boas. Logo no prefácio do livro Arte Primitiva, dois princípios e um objetivo geral são destacados. O autor parte da "igualdade fundamental dos processos mentais" e da "consideração de todo fenômeno cultural como o

Dossiê Consumo e Subjetividade 
resultado de acontecimentos históricos" para "determinar as condições dinâmicas sob as quais os estilos artísticos crescem" (BOAS, 2014, p. 13-18). O objeto do livro, ou seja, a chamada "arte primitiva", ao longo da obra não recebe uma definição precisa, mas sugere nominalmente algo como o produto estilizado da expressão artística de sociedades ágrafas (ALMEIDA, 1998). Essa arte primitiva é referida, primariamente, ao chamado campo decorativo e ornamental, cuja fonte é o conjunto das obras de indústria artísticas - entalhe, cestaria, tecelagem, trabalho em metal, cerâmica. O fio condutor do argumento, considerando o material disponível - muito variado e que nos alça voo pelas mais diversas e distantes criações humanas específicas - oferece o terreno sobre o qual florescem reflexões de caráter geral. É sobre tais reflexões, e não sobre os casos particulares, que passaremos a tratar, sumariamente, as questões de origem, forma e conteúdo da expressão artística

Franz Boas (2014, p. 14) parte de uma aproximação entre a experiência estética e a experiência técnica para qualificar a expressão artística, pois considera que:

O juízo de perfeição da forma técnica é essencialmente um juízo estético (...) onde quer que se desenvolva um tipo definido de movimento, uma sequência definida de tons ou uma forma fixa, eles se tornarão um padrão através do qual a sua perfeição, ou seja, sua beleza, será medida.

É o princípio formal que caracteriza o primeiro movimento que dá origem à arte como valor estético. Poderíamos dizer que subsiste, nessa perspectiva, um formalismo metodológico, ou mesmo um primado da forma. No entanto, há ainda outra fonte a ser considerada: "É essencial termos em mente a fonte dupla do efeito artístico, a primeira baseada apenas na forma, a segunda em ideias associadas à forma" (BOAS, 2014. p. 16). Franz Boas não é indiferente ao conteúdo. A expressão de pensamentos e emoções associadas ao objeto artístico, ao lado do valor estético, qualifica um tipo de valor emocional, uma intimidade entre a forma convencional e as ideias expressivas, seja quando se comunica uma experiência do passado ou quando se representa um símbolo.

Desse ponto de vista, é possível dizer que há uma precedência da forma em relação ao conteúdo, uma vez que "a significância da forma artística não é universal, e também não podemos demonstrar que ela seja necessariamente mais antiga que a forma" (BOAS, 2014, p. 16). Ainda que aspectos aparentemente puramente formais sejam amplamente disseminados no espectro da chamada arte primitiva, considerando o caso do campo decorativo, nota-se uma associação entre o estilo - princípio de organização estética convencional - e as ideias veiculadas pelas obras de uma expressão artística. Para além da atração formal, uma obra logra êxito em comunicar pensamentos e emoções nos casos em que as associações de conteúdo sejam amplamente reconhecidas em formas fixas, quando as reações a determinado padrão vazam os limites da intencionalidade individual e reverberam nos estados emocionais coletivos. Tudo se passa como se a significância fosse um momento posterior e condicionado pela precedência da tradição:

Dossiê Consumo e Subjetividade 
"o elemento formal que caracteriza o estilo é mais antigo que o tipo particular de representação" (BOAS, 2014, p. 332-3).

Vimos que a origem da expressão artística, seja nos casos das artes gráficas ou plásticas, será buscada no estudo do valor artístico formal dos objetos de manufatura primitiva. Afinal, “a origem dos hábitos motrizes provavelmente deve ser procurada nos processos técnicos, e a origem dos arranjos nos mesmos processos e nas formas de utensílios familiares" (BOAS, 2014, p. 144). Este é o primeiro plano sobre o qual uma atitude estética se projeta sobre as obras do engenho humano. Para fazer referência a esse elemento primordial, Franz Boas destaca a ideia de virtuosismo técnico, sendo o virtuose aquele artista que atingiu um alto gabarito de conhecimento e domínio técnico na execução de sua obra. O virtuosismo refere-se ao "controle completo dos processos técnicos" dado pela "regularidade automática do movimento", uma condição sem a qual não há desenvolvimento artístico (BOAS, 2014, p. 24-5). Portanto, a origem estaria na "percepção exuberante das formas" e na "apreciação do valor estético da perfeição técnica" (BOAS, 2014, p. 28-9). Essa fonte primordial está assentada sobre uma função psicológica básica: o prazer do virtuose em dominar dificuldades e criar formas complexas a partir da regularidade da técnica e da uniformidade da superfície. É possível perceber essa qualidade fundamental nas formas elementares da simetria e da repetição rítmica.

Dossiê Consumo e Subjetividade

Arquivos do CMD, Volume7, N.2. AGo/Dez 2018
A questão da expressão artística supera o elemento formal, quando este já se encontra resolvido pelo virtuosismo da técnica, na medida em que procura representar objetos naturais, ideias e emoções. Por isso, se diz que "a combinação entre forma e conteúdo dá à arte representativa um valor emocional completamente diferente do efeito estético puramente formal" (BOAS, 2014, p. 73). Assim, além da função técnica, há uma função representativa da expressão artística. Franz Boas destaca ao menos dois métodos decorrentes desta outra função, quais sejam: o método em perspectiva e o método simbólico. Entre essas duas alternativas de representação argumenta-se não haver uma linha evolutiva, pois ambas teriam fontes psicológicas distintas. Ao sustentar essa posição, Franz Boas se contrapõe ao conjunto de teorias que supõe a antecedência da representação em perspectiva (realista) com base na imitação de formas naturais em relação à representação simbólica ou ao geometrismo convencional, os quais seriam degenerações do primeiro tipo.

O fundamento da função representativa é a separação entre a forma da representação artística e a forma do objeto natural, ou seja, mesmo no caso do método em perspectiva, o ato representativo consiste na distância estabelecida entre a expressão humana e a realidade imediata. A diferença entre os métodos de representação refere-se ao modo de composição do campo decorativo, a disposição formal da figura representada. No caso do método em perspectiva, é dada maior atenção ao contorno geral em detrimento do detalhamento específico. A perspectiva privilegia uma impressão 
visual momentânea do todo, do corpo inteiro e o seu delineamento mais bruto. Por outro lado, o método simbólico confere maior atenção ao detalhamento específico, inflando os aspectos característicos e justapondo-os em sacrifício do realismo. A representação simbólica se esforça na ênfase dos elementos constitutivos, oferecendo uma espécie de caricatura. Se na função técnica temos a simetria e o ritmo enquanto formas primitivas, na função representativa teríamos a perspectiva e a ênfase. Assim como a simetria e o ritmo se equilibram na variação do virtuosismo da técnica empregada, a perspectiva e a ênfase também podem se equilibrar na variação do estilo representativo local.

Forma e conteúdo se interpenetram, ainda que o elemento formal seja o pré-requisito da apreciação estética. A técnica, impondo forma à matéria, qualifica o estilo de representação, assim como um determinado estilo de representação exige o emprego daquela técnica particular mais adequada. Atribuir uma significância a uma forma representativa tecnicamente executada corresponde a uma terceira função: a função significativa. A ela corresponde à operação de somar um valor emocional a um valor estético. O trecho a seguir é ilustrativo:

Como as representações que pretendem ter valor artístico são feitas na técnica mais altamente desenvolvida, não surpreende que o estilo formal da técnica ganhe influência sobre a forma da representação. (...) Quanto mais profunda a influência do elemento formal e decorativo sobre o método de representação, mais provável será que os elementos formais recebam um valor emocional. Estabelece-se uma associação entre estas duas formas que leva, por um lado, à convencionalização do desenho representativo e, por outro, à imputação de significância a elementos formais. Seria muito arbitrário pressupor um desenvolvimento unilateral do representativo para o formal ou vice-versa, ou mesmo falar de uma transformação gradual de uma forma representativa para uma convencional, porque a própria representação artística só pode proceder com base nas formas desenvolvidas tecnicamente. (BOAS, 2014, p. 90)

Essa simbiose entre forma e conteúdo se mostra mais evidente na balança entre convenção, representação e significância. Tornar convencional é fixar uma forma para um conteúdo, seja representativo ou significativo. Imputar significância é reconhecer um conteúdo adicional na forma, além do seu aspecto técnico e representativo. Acima, temos o esboço da relação entre forma e conteúdo a partir do texto de Franz Boas. Vimos que a origem da expressão artística se encontra nos hábitos motrizes do virtuosismo técnico. Tais hábitos variam de acordo com os estilos locais.

$\mathrm{Na}$ outra ponta dessa reflexão, passaremos a tratar a origem da expressão artística, considerando forma e conteúdo, pelo viés da ordenação cosmológica e da experiência religiosa. Aby Warburg, refletindo sobre as suas memórias de viagem à região dos índios pueblos na América do Norte, confessa uma aversão ao caráter formal da história da arte, então confinada a uma visão estetizante da imagem. Na contramão, uma teoria vigorosa da imagem - e da imagem enquanto símbolo - sustenta-se por uma compreensão do nexo orgânico entre arte e religião, algo manifesto com maior nitidez na experiência do chamado "homem primitivo".

Dossiê Consumo e Subjetividade 
No conjunto da obra, é possível precipitar uma questão fundamental: que influência exerce o paganismo nas formas culturais posteriores ao seu advento? Paganismo, evidentemente, é um termo muito impreciso. Afinal, seria tudo aquilo que escapa à cristianização ou às chamadas religiões mundiais legadas da Era Axial? Uma intuição nos leva a crer que o termo "paganismo" refere-se a uma situação primordial sobre a qual a cultura humana “(...) labora em seu refinamento, em sua suplantação e em sua substituição" (WARBURG, 2015, p. 253). O paganismo seria o ponto firme da indestrutibilidade do homem primitivo, aquilo sobrevive em todas as suas obras póstumas, cuja inclinação se acha no culto mágico e na veneração dos fenômenos naturais - o espaço de devoção e ordenação cosmológica do mundo. Na trilha que parte do paganismo primitivo, passando pelo paganismo da antiguidade clássica, até a moderna cultura do Renascimento florentino e da Reforma alemã, somos conduzidos a colocar em perspectiva o processo da racionalização humana, as contaminações entre povos, os efeitos da secularização em marcha e os resquícios da veneração mágica, um palimpsesto rebelde à decifração mais imediata.

Em seus primeiros trabalhos, Warburg (2015) se colocava a questão da influência da antiguidade pagã clássica no chamado Renascimento italiano florentino, especialmente nas obras de Sandro Botticelli e Albreht Dürer. Importava ao autor saber qual a fonte clássica - textos e imagens - do movimento dos corpos representados e os índices pictóricos dessa inspiração. Nos detalhes, percebeu o movimento nos trajes, nos acessórios, nos cabelos, nos pés, enfim, nos gestos, e o modo como uma história cultural - em meio a artistas, eruditos, poemas, objetos e referências materiais conduziu esses elementos, na forma de modelos de representação, à formação de um estilo artístico. Em outra oportunidade, Warburg (2015), olhando para a Reforma protestante alemã, observa como a data de nascimento de Lutero tornou-se alvo de controvérsias astrológicas, subordinando a consagração do novo profeta antipático à astrologia e, no limite, iconoclasta - a uma causalidade mitológica amplamente disseminada no seu tempo histórico. Sugestivamente, o método desse autor se revela como num jogo de correspondências pelo tempo e pelo espaço, algo bem condensado no conceito de "sobrevivência" (Nachleben), ou, como se deu a traduzir, a vida póstuma (DIDI-HUBERMAN,2012) dos fragmentos de cultura, elevados sob o ângulo das imagens. O mesmo ocorre com o símbolo pagão da serpente, cujo anacronismo assombroso manifesta-se como um sintoma da sublimação religiosa em diversas oportunidades da expressão artística humana (WARBURG, 2015).

A ideia suscitada pela palavra palimpsesto parece adequada para descrever esse método de pensamento. Palimpsesto, como se sabe, é uma escrita sobre outra escrita, um pergaminho onde um texto mais novo sobrepõe-se a um texto mais antigo, uma espécie de reciclagem vocabular, camadas e mais camadas de um sedimento histórico de longa duração. A memória inconsciente, que é o assunto por excelência de uma psicologia histórica da expressão, se revela nos elementos da cultura tal como o palimpsesto, ou seja, a sobreposição de imagens, símbolos e palavras, as quais traem a

Dossiê Consumo e Subjetividade 
lógica e a linearidade do tempo para dar vez ao sintoma (DIDIHUBERMAN, 2012), à sobrevivência. Um texto mais antigo não desaparece, metamorfoseia. Tal é o sentido da Nachleben, uma plasticidade da expressão no tempo. Por outro lado, se sobrevive é por conta da carga afetiva mobilizadora, o poder de evocação sentimental da própria expressão, uma força empática que impõe resistência à sua desaparição.

Este último aspecto é crucial para pensar a relação entre forma e conteúdo no pensamento de Aby Warburg. Trata-se da dimensão condensada no conceito de Pathosformeln - as fórmulas patéticas -, a expressão de estados emocionais por via dos gestos em movimento, cristalizados em índices pictóricos. Forma e conteúdo, portanto, indissociáveis, exercem uma força de atração psíquica através da imagem mnêmica, cujo efeito é a penetração recíproca - empática - entre sujeito e objeto. Já nos estudos sobre Botticelli, Warburg (2015, p. 27) salientava que o objetivo de uma "estética psicológica" é a compreensão do "ato estético da "empatia' como uma força formadora de estilo". Mas qual seria o sentido da empatia (Einfühlung)? Que lugar ocupa o ato estético da empatia para uma teoria da imagem calcada na psicologia histórica da expressão?

Warburg busca o sentido de "empatia" na experiência elementar do chamado "homem primitivo", uma vez que o considera uma figura heurística do pensamento humano in statu nascendi, sendo a imagem espécie de grafia embrionária de um longo processo de racionalização. A empatia, muito além da projeção de si no outro, algo a mais do que a mera transposição do Eu na coisa externa, também revela o sentido contrário, ou seja, o outro que habita no si mesmo, a coisa externa interiorizando-se, a penetração recíproca dos termos constitutivos. O conceito de empatia revela a sua potência quando pensamos a noção de tragédia da cultura: "Essa é a tragédia do ser humano, que, ao manipular as coisas, amplia-se para além de sua extensão orgânica" (WARBURG, 2015, p. 269). Para melhor ilustrar essa noção de tragédia da cultura, um tema muito recorrente na época em que Warburg escreveu, segue um trecho de Georg Simmel apresentando o fundamento desse conceito $(2005$, p. 76$)$ :

O homem não se ordena à realidade natural do mundo como o animal, antes ele se arranca dela e se contrapõe a ela, exigindo, lutando, violentando e sendo violentado com este primeiro grande dualismo, inicia-se o processo infindável entre o sujeito e o objeto. (...) Deste modo, o sujeito encontra-se perante a arte e o direito, a religião e a técnica, a ciência e a moral não apenas coberto aqui e repelido ali por seu conteúdo, já fundido a eles como se estes fossem uma parte do seu Eu, logo em uma relação de estranheza e intocabilidade com eles. (...) A idéia de cultura encontra-se no meio deste dualismo.

Temos clareza de que o problema da "tragédia da cultura" é central para Warburg quando este, ao escrever as primeiras linhas da sua última contribuição - Mnemosine -, e que se pretendia uma síntese de um projeto de conhecimento conduzido ao longo de toda uma vida, diz:

Dossiê Consumo e Subjetividade 
${ }^{1}$ Aliás, não seria esta a premissa da frase "a seca ensina a fazer magia e a rezar"?
A criação consciente da distância entre si e o mundo exterior pode ser designada como o ato básico da civilização humana; tão logo esse espaço intermediário se torne o substrato da figuração artística, satisfazem-se as precondições para que tal consciência da distância possa se tornar uma função social duradoura, que, por meio do ritmo da imersão na matéria e da emersão na sofrósina, indica aquele circuito entre a cosmologia das imagens e a dos signos cuja adequação ou cujo colapso como instrumento espiritual de orientação são justamente o que indica o destino da cultura humana. (WARBURG, 2015, p. 363).

O elemento trágico, que encerra um dualismo constitutivo entre su jeito e objeto, refere-se, sobretudo, a uma situação mediante a qual o indivíduo, afirmando a sua subjetividade, perdese em meio a uma objetividade histórica que o constitui e ultrapassa. Para um sujeito que se perde no objeto, o modo mais elementar de conhecer alguma coisa é por efeito da incorporação, quer dizer, um conhecimento por incorporação (DIDI-HUBERMAN, 2012). E se a imagem é a grafia elementar dessa forma de pensamento in statu nascendi, então nos importa compreender como o olhar incorpora o objeto(DIDI-HUBERMAN, 2012), levando a cabo uma relação de empatia de mão dupla. Warburg, dessa maneira, busca na ornamentação simbólica e no ritual da dança mágica - na região dos índios pueblos da América do Norte - uma fonte de acesso para compreender o modus operandi desse processo empático:

Perdido num estado intermediário entre o manipular e o portar, a perda e a afirmação, o sujeito vai ao objeto. Em termos cinéticos, o homem está presente, mas tem uma ampliação anorgânica de seu Eu, que o cobre por inteiro. A perfeição da perda do sujeito no objeto aflora na ação de sacrifício, que incorpora elementos ao objeto.
Transformação imitadora pela mímica; exemplo: o culto da dança mascarada. (WARBURG, 2015, p. 280)

À metamorfose do universo inanimado o homem primitivo responde com sua própria metamorfose. Ele em certa medida translada para dentro de si a causalidade própria à metamorfose dos eventos. À metamorfose da planta, que do grão de milho vai ao fruto, ele responde com sua metamorfose pessoal - como dançarino mascarado - na condição de senhor desse processo de maturação. (WARBURG, 2015, p. 282)

O conhecimento por incorporação - o olhar que apreende o objeto querendo dominá-lo, portanto, concebê-lo - é possibilitado pela mimese, quer dizer, pela empatia mimética. Entendemos melhor quando por mimese não queremos dizer meramente imitação, mas metamorfose, nas palavras de Warburg (2015, p. 276) "tudo o que vivenciamos é metamorfose". O homem primitivo, dessa maneira, perplexo diante do mundo, emula a semelhança dos fenômenos naturais por empatia mimética e busca apreender o imponderável por antecipação: "Faz parte da magia a antecipação, por meio da mímica imagética, de um acontecimento futuro que é condicionado pela vontade" (WARBURG, 2015, p. 282). A dança mascarada e o seu respectivo efeito de vinculação simbólica, querendo interferir magicamente no curso dos eventos naturais, faz tão parte da luta pela sobrevivência quanto a técnica instrumental de aquisição do alimento ${ }^{1}$. O homem primitivo seria, antes de tudo, um devorador de símbolos, e essa é a sua primeira necessidade: "as medidas sociais para garantir os meios de subsistência são, portanto, esquizoides: nelas, a magia e a técnica colidem". (WARBURG, 2015, p. 218).

Dossiê Consumo e Subjetividade 
As considerações colocadas acima revelam uma espécie de antropologia filosófica warburguiana, talvez melhor compreendida quando o autor traça uma ligação entre o que chama de "homem apanhador" (Greifmenschen) e "homem conceituador" (Begriffsmenschen). O homem apanhador, cujo órgão mais essencial é a mão, e o sentido mais desenvolvido é o tátil, baseia-se numa situação primordial do homem primitivo em que a coleta cumpria a principal atividade e meio de sobrevivência, portanto, a manipulação das coisas do mundo e o seu desfrute imediato. Assim se poderia dizer que o homem primitivo pensa, primeiramente, pelas mãos, quando apanha, porta e manipula os objetos de seu entorno. No caminho de sua evolução, o homem primitivo aprende a caçar e, depois, a plantar, exercendo um crescente domínio tecnológico sobre a natureza. A disposição mental de referir-se a um futuro consecutivo - previsão, cálculo e planejamento -, fabricando, inclusive, instrumentos para dar cabimento às ações de sobrevivência, desenvolve uma capacidade de conceituar, operação de distanciamento imaginativo em relação à realidade imediata. No entanto, esses tipos ideais só nos interessam à medida que pensamos o meio termo, o intermediário entre o apanhar e o conceituar: "entre o homem apanhador, que pega as coisas, e o comedido homem conceituador está aquele que vincula por meio de símbolos" (WARBURG, 2015, p. 219). O símbolo é aquilo que há de palpável no conceito.

Por isso, os objetos do mundo natural - plantas, animais e fenômenos meteorológicos, por exemplo - são, a um só tempo, coisa e conceito, ungidos pela vinculação simbólica. O totemismo corresponde a esta operação mental elementar. Em um dos exemplos usados por Warburg, referindo-se à ornamentação simbólica dos pueblos, há uma cerâmica que carrega consigo a imagem de um símbolo heráldico, o pássaro, que, no ideário mítico dos índios, sinaliza uma veneração do culto fúnebre:

A ave torna-se hieróglifo, que já não é feito para ser visto, mas lido. Temos um grau intermediário entre a imagem do real e o signo, entre a imagem realista do espelho e a escrita. Nesse gênero de tratamento ornamental dos animais é possível ver de imediato como tal maneira de ver e de pensar pode levar à escrita simbólica por imagens. (WARBURG, 2015, p. 208)

Um animal maravilhoso, ao que parece o produto mais concreto da fantasia lúdica, é, in statu nascendi, uma abstração plena de labor conceitual. (WARBURG, 2015, p. 262-3)

Quando um animal torna-se um hieróglifo, ou seja, uma abstração plena de labor conceitual, a distância entre a imagem do real e o signo se estreita, o intermediário se realiza por vinculação simbólica; abre-se uma margem para a escrita simbólica por imagens, melhor dizendo, uma forma de pensamento por imagens. Entendemos melhor como essa forma de pensamento se efetiva, inclusive corporalmente, quando pensamos na dança mascarada. A dança humiskachina, em Oraibi, cujo objetivo é o exercício da influência mágica sobre o crescimento do milho, exemplifica muito bem o processo de vinculação simbólica e o modo como se dá a empatia mimética:

Dossiê Consumo e Subjetividade 
Estamos aqui, portanto, no âmbito do mais perfeito culto arbóreo e animista, que, como sabemos pelos trabalhos de Mannhardt, segue existindo no paganismo europeu, nos costumes hodiernos ligados à colheita, como parte das concepções populares primárias da mitologia humana universal. Trata-se aqui do vínculo entre a força da natureza e o ser humano, isto é, de criar o symbolon, a ação mágica realmente vinculadora, o que se faz ao lançar um termo mediador - nesse caso uma árvore, que está mais próxima à terra do que o homem, já que nela se enraíza. Essa árvore é o mediador que conduz ao mundo inferior. As penas são levadas no dia seguinte rochedo abaixo até uma fonte do vale, onde são plantadas ou penduradas como oferendas. Devem justamente fazer com que as preces atuem em prol da fertilidade, para que milho cresça e se torne abundante. (WARBURG, 2015, p. 231-2)

Paralelamente, a dança da serpente, em Walpi - que, para Warburg (2015, p. 234), seria índice de um estágio ainda mais primordial da dança mágica - oferece uma situação mediante a qual “(...) os dançarinos e o animal vivo formam uma unidade mágica (...)":

A cerimônia da serpente em Walpi está, portanto, situada entre a empatia mimética da imitação e o sacrifício sanguinário, já que, nela, o animal é agora ele próprio introduzido como colaborador no culto da forma mais crua possível, e não para ser sacrificado, mas - como o páho - para atuar como mediador em prol da chuva, na medida em que acaba sendo devolvido à terra. (WARBURG, 2015, p. 234)

A serpente não é, portanto, sacrificada durante essa dança, mas apenas convertida - pela consagração e pela mímica influenciadora - em emissária e despachada para que, retornando às almas dos mortos, produza, em forma de raio, a trovoada no céu. (WARBURG, 2015, p. 236)
O que Warburg parece querer assinalar com a discussão sobre a dança mascarada é, afinal, uma operação cognitiva correspondente a uma necessidade psicológica primeira: a ideia de causa:

A ideia de causa - e essa é a conquista científica dos assim chamados primitivos - é transmutável entre o animal e o homem, e a forma mais crassa dessa transmutação acontece precisamente na dança. Por meio da música que lhe é próprio e - como na dança com as cascavéis - até mesmo com o apropriar-se da própria criatura viva. (WARBURG, 2015, p. 264)

Se a imagem é um ponto de partida, pois revela a grafia do pensamento simbólico in statu nascendi, a ordenação cosmológica do mundo é o ponto de chegada, uma vez que a fantasia mitológica torna possível o absurdo, uma ferramenta de proteção contra o imponderável da natureza hostil. Aquilo que há de ancestral na expressão artística deve-se ao processo de vinculação simbólica, precisamente o sentido atribuído aos fenômenos do mundo externo e a tentativa de influenciá-los. A causalidade mitológica, portanto, preenche o conteúdo do pensamento simbólico, que é a principal fonte da figuração artística em Aby Warburg. Por isso, a forma, despida de qualquer pureza, portanto, entrelaçada com um conteúdo correspondente, se mostra, antes de tudo, como uma força ativa que canaliza energias conservadas de experiências intensas, individuais e coletivas. Essas experiências intensas são expressivas de estados emocionais geradores de comoção; uma comoção é sentida mediante o efeito empático da imagem, seja quando o corpo dança e 
realiza a mimese, seja quando o olhar captura o objeto e faz a leitura do símbolo.

Ao final dessa reflexão, podemos perceber semelhanças e diferenças entre os dois autores abordados. A questão de fundo, ou seja, a origem da expressão artística a partir da relação entre forma e conteúdo, encontra, aqui, duas alternativas: por um lado, a origem está nos hábitos motrizes, na fabricação técnica dos objetos, cuja necessidade psicológica se dá pelo prazer do virtuose em dominar formas complexas; por outro lado, a origem está na ordenação cosmológica do mundo, no efeito de vinculação simbólica, cuja necessidade psicológica se dá pela empatia mimética que visa apreender o imponderável. Do mesmo modo, vimos que essas alternativas esboçam maneiras distintas de conceber a relação entre forma e conteúdo, quer dizer: por um lado, forma e conteúdo são momentos apartados, o valor estético precede o valor emocional, o domínio técnico da forma é o que garante o efeito propriamente artístico, sendo o conteúdo, a reação emocional do coletivo, uma espécie de significância incrementada; por outro lado, forma e conteúdo são indissociáveis, a arte se aproxima da experiência religiosa, portanto, os efeitos formais canalizam forças energéticas intensas, inseparáveis dos elementos estéticos constitutivos.

\section{Referências}

ALMEIDA, Kátia. Por uma semântica profunda: arte, cultura e história no pensamento de Franz Boas. Revista Mana, no 4, v. 2, p. 7-34, 1998.

Dossiê Consumo e Subjetividade

Arquivos do CMD, Volume7, N.2. AGo/Dez 2018
BOAS, Franz. Arte Primitiva. Petrópolis-RJ: Vozes, 2014.

DIDI-HUBERMAN, Georges. A Imagem Sobrevivente. História da arte e tempo dos fantasmas segundo Aby Warburg. Rio de Janeiro: Contraponto, 2012

GUIDI, Benedetta; BOAS, Franz; WARBURG, Aby. Aby Warburg and Franz Boas: Two Letters from the Warburg Archive: The Correspondence between Franz Boas and Aby Warburg (19241925). Revista Anthropology and Aesthetics no 52, p. 221-230, 2007.

SIMMEL, Georg. O Conceito e a Tragédia da Cultura In. Simmel e a Modernidade. Brasília: Editora UnB, 2005.

WARBURG, Aby. Histórias de Fantasma para Gente Grande. São Paulo: Companhia das Letras, 2015. 